\title{
Stability-indicating UV/Vis Spectrophotometric Method for Diazepam, Development and Validation
}

\author{
S. CHAKRABORTY1 , S. SHARMIN', S. R. RONY1', S. A. I. AHMAD AND MD. H. SOHRAB ${ }^{1 *}$
}

Department of Biotechnology and Genetic Engineering, Mawlana Bhashani Science and Technology University, Santosh, Tangail-1902, ${ }^{1}$ Pharmaceutical Sciences Research Division, Bangladesh Council of Scientific and Industrial Research, BCSIR Laboratories, Dhaka, Dr. Qudrat-I-Khuda Road, Dhanmondi, Dhaka-1205, Bangladesh

\section{Chakraborty, et al.: UV/Vis Spectrophotometric Method for Diazepam}

\begin{abstract}
A stability-indicating UV/Vis spectrophotometric method was developed and validated for estimation of diazepam in tablet dosage form. The proposed method utilized a Specord 250 plus PC double beam spectrophotometer using $1.0 \mathrm{~cm}$ quartz cells and all determinations were made at a wavelength of $231 \mathrm{~nm}$ in methanol:distilled water (1:1). Experiments were designed for determining linearity, limit of detection and quantitation, accuracy, precision and specificity of this analytical method as per the International Organization for Standardization guidelines. The drug substance and the drug product were exposed to thermal, photolytic, hydrolytic, and oxidative stress conditions, and the stressed samples were analyzed using the proposed method to demonstrate the specificity of the method. The proposed method was found to be linear in the concentration ranges from 3.096-15.480 $\mu \mathrm{g} / \mathrm{ml}$ with the linear correlation coefficient of $R^{2}=0.999$ and the mean recoveries were 98.36 to $100.72 \%$. Although the degradation products of stressed condition had not been identified, the method had been able to detect the changes due to stress condition. The stated method can be used as stability indicating method with high degree of linearity, accuracy and precision for assay of diazepam in routine pharmaceutical analysis of tablets.
\end{abstract}

Key words: Validation; forced degradation, linearity, specificity, UV/Vis spectrophotometer

Method validation may be regarded as one of the most accustomed areas in analytical chemistry. The International Organization for Standardization defines validation as the confirmation by examination and provision of objective evidence that the particular requirements for a specified intended use are fulfilled ${ }^{[1]}$. This enunciation primarily implies that a detailed examination has been carried out and gives evidence that the utility of the analytical method with a high degree of accuracy consequently produces results that are fit for purpose ${ }^{[1]}$. The use of validated methods is exigent for an analytical laboratory to parade its qualification and proficiency ${ }^{[2]}$.

Stability testing forms a weighty part of the process of pharmaceutical product development. The motive of stability testing is to provide testimony on how the quality of a drug substance or drug product varies with time under the influence of various environmental factors. Stability testing by forced degradation involves degradation of drug products and drug substances under the influence of more severe than accelerated conditions such as hydrolysis, temperature, humidity,

*Address for correspondence E-mail: psrd_bcsir@yahoo.com

March-April 2018 and light ${ }^{[3,4]}$. Sense of the stability of molecule helps in selecting proper formulation and package as well as in providing proper storage conditions and shelf life, which is fundamental for regulatory documentation ${ }^{[4]}$. This work deals with development and validation of a new stability-indicating spectrophotometric method for the routine appraisement of diazepam in bulk and tablet dosage form to make the assay test affordable and pecuniary.

Diazepam $\left(\mathrm{C}_{16} \mathrm{H}_{13} \mathrm{ClN}_{2} \mathrm{O}\right)$ is a sedative and hypnotic drug of benzodiazepine-2-one group ${ }^{[5-7]}$. Basically, it is highly lipophilic and rapidly absorbed after oral administration ${ }^{[8]}$. Reaction between 2-amino5-chlorobenzophenone and glycine ethyl ester in pyridine leads to 7-chloro-1,3-dihydro-5-phenyl2H-1,4-benzodiazepine-2-one, which subsequently

This is an open access article distributed under the terms of the Creative Commons Attribution-NonCommercial-ShareAlike 3.0 License, which allows others to remix, tweak, and build upon the work non-commercially, as long as the author is credited and the new creations are licensed under the identical terms

Accepted 26 February 2018

Revised 28 July 2017

Received 04 August 2016

Indian J Pharm Sci 2018;80(2):366-373 
is methylated with methyl sulphate in the presence of sodium ethoxide to yield diazepam (fig. 1) ${ }^{[9]}$. It is effective in providing symptomatic relief of tension and anxiety ${ }^{[6-9]}$ and acts as an anticonvulsant and anaesthetic by potentiating GABAergic neurotransmission ${ }^{[6-10]}$.

$\mathrm{UV} / \mathrm{Vis}$ spectrophotometry is one of the most frequently employed techniques in pharmaceutical analysis, which is simple, rapid, specific, precise, accurate and applicable to small quantities of compounds. The main principle of UV/Vis spectrophotometry is the measurement of the amount of UV or visible radiation absorbed by a substance in solution. BeerLambert law is the fundamental law that governs the quantitative spectrophotometric analysis, which states that the intensity of a beam of parallel monochromatic radiation decreases exponentially with the number of absorbing molecules as it passes through a medium of homogeneous thickness ${ }^{[11]}$.

\section{MATERIALS AND METHODS}

UV/Vis spectra were recorded on a Specord 250 plus PC double beam spectrophotometer using $1.0 \mathrm{~cm}$ quartz cells. All weighing's were done on an electronic balance (A\&D Company Ltd., USA). Bath sonicator (Wisd Laboratory Instruments, Germany) was used to aid dissolution. Glassware used in each procedure were bleached entirely with detergent and rinsed thoroughly with double-distilled water and dried in a hot air oven. Pure drug samples of diazepam were obtained from Beximco Pharmaceuticals Ltd., Dhaka, Bangladesh. All other chemicals and reagents used were of analytical grade. Methanol, sodium hydroxide $(\mathrm{NaOH})$, hydrochloric acid $(\mathrm{HCl})$ and hydrogen peroxide $\left(\mathrm{H}_{2} \mathrm{O}_{2}\right)$ were purchased from Active Fine Chemicals Ltd., Shegun Bagicha, Bangladesh. Four locally available
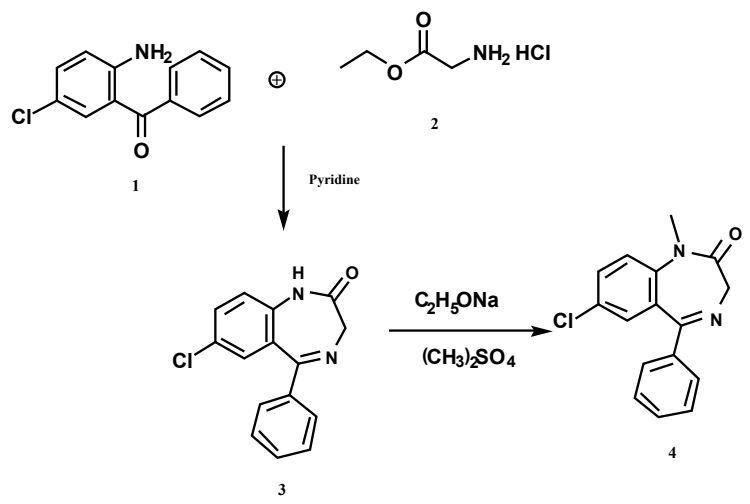

Fig. 1: Synthesis of diazepam ${ }^{[9]}$

1: 2-amino-5-chlorobenzophenone; 2: glycine ethyl ester; 3: 7-chloro-1,3 dihydro-5-phenyl $2 \mathrm{H}$-1, 4-benzodiazepin-2-one; 4: diazepam brands of diazepam tablets coded as $\mathrm{D}_{1}, \mathrm{D}_{2}, \mathrm{D}_{3}$ and $\mathrm{D}_{4}$ have been purchased from a local pharmacy to conduct the assay with the developed method.

\section{Selection and standardization of the solvent:}

In the preliminary trial, five different compositions of solvent were selected that included distilled water, methanol, methanol:distilled water (1:1), $0.1 \mathrm{~N} \mathrm{HCl}$ and phosphate buffer ( $\mathrm{pH}$ 7.4). Methanol:distilled water $(1: 1)$ was selected as the appropriate media for ease of sample preparation, solubility of the drug and cost of the solvent. The wavelength maximum of diazepam was found to be $231 \mathrm{~nm}$. Stock solution of diazepam standard was prepared to get an approximate concentration of $5 \mu \mathrm{g} / \mathrm{ml}$ and sonicated for $4 \mathrm{~min}$ in bath sonicator.

\section{Linearity:}

Response function was determined by preparing standard solution at thirteen different concentration levels ranging from 3.096-15.480 $\mu \mathrm{g} / \mathrm{ml}$ in UV/Vis spectrophotometric method. The limit of detection (LOD) and limit of quantitation (LOQ) were separately determined based on standard deviation of the Y-intercept and the slope of the calibration curve as per International Council for Harmonisation $(\mathrm{ICH})$ guidelines $^{[12]}$. LOD $=3.3 \times\left(\right.$ standard deviation $^{2}$ of Y-intercept/slope of the curve) and LOQ = $10 \times 2$ (standard deviation of Y-intercept/slope of the curve).

\section{Accuracy:}

Accuracy of the method was determined by performing the recovery experiment. This experiment was performed at five levels equivalent of 80 to $120 \%$ of nominal concentration. Three replicate samples of each concentration level were prepared and the percent recovery at each level $(n=15)$ were determined.

\section{Precision:}

The precision of the instrument, relative standard deviation (RSD) was checked by repeated scanning of samples $(n=6)$ for diazepam standard without changing the parameter of the proposed spectrophotometric method. Intra-assay and inter-assay precision (RSD) data were obtained by repeatedly analysing, in one laboratory on one day (1st, 3rd, and 8th h) and several days within a week (on day 1, 3, 5 and 7), aliquots of a homogeneous sample, respectively. Percent RSD = standard deviation of measurements/mean value of measurement $\times 100$. 


\section{Assay:}

The assay of four marketed brands $\left(\mathrm{D}_{1}, \mathrm{D}_{2}, \mathrm{D}_{3}\right.$ and $\mathrm{D}_{4}$ ) was carried out with this proposed method at $231 \mathrm{~nm}$ using following Eqn., drug content (mg/tablet) $=($ sample absorbance $/$ standard absorbance $) \times($ standard weight $/$ sample weight $) \times$ average weight $\times$ standard potency/100.

\section{Specificity:}

Specificity detects quantitatively the analyte in presence of component that may be expected to be present in the sample matrix. Commonly used excipients, such as purified talc, magnesium stearate, Povidone K-30 and lactose were mixed at appropriate amount and dissolved in the solvent system in amount equivalent to the weight of excipient present in portion of sample preparation as per the assay method. At first, different excipient concentration level (80-120\% of nominal concentration present in assay preparation) were spiked with nominal concentration of drug substance followed by nominal concentration of excipient at different concentration level of drug substance (80-120\% of nominal concentration present in assay preparation) and then absorbance was measured and calculation done to determine quantity of drugs.

The responses of the standard diazepam, marketed product and excipient of stressed condition were also compared with the response of the same solution of unstressed condition to establish the stability indicating nature of the developed UV/Vis method as part of the forced degradation studies.

\section{Forced degradation study:}

Here, the drug substance and one out of the four tested marketed drug product $\left(\mathrm{D}_{1}\right)$ have undergone forced degradation study under neutral, acid, and base hydrolytic as well as oxidative, photolytic and thermolytic stress conditions ${ }^{[13]}$. Only thermal degradation of drug substance and drug product was carried out in solid state. Solutions were prepared by dissolving drug substance or drug product in distilled water, aqueous $\mathrm{HCl} / \mathrm{NaOH} / \mathrm{H}_{2} \mathrm{O}_{2}$ solution, or solvent to obtain a concentration of $50 \mu \mathrm{g} / \mathrm{ml}$ and later diluted with the solvent of methanol:distilled water (1:1) to achieve an approximate concentration of $5 \mu \mathrm{g} / \mathrm{ml}$. Finally, a spectral scan ranges from $200-400 \mathrm{~nm}$ in UV/Vis spectrophotometer was performed to take absorbance at different days for observing degradation.

Neutral hydrolysis of drug substance and drug product in solution state was conducted with distilled water at room temperature and $60^{\circ}$ for $7 \mathrm{~d}$. Acid hydrolysis of drug substance and drug product in solution state was directed with $0.1 \mathrm{~N} \mathrm{HCl}$ at room temperature and $60^{\circ}$ for $7 \mathrm{~d}$. Base hydrolysis of drug substance and drug product in solution state was guided by $0.1 \mathrm{~N}$ $\mathrm{NaOH}$ solution at room temperature and $60^{\circ}$ for 2 d. For oxidative stress, sample solutions of drug substance and drug product in $3 \% \mathrm{H}_{2} \mathrm{O}_{2}$ were kept at room temperature and $60^{\circ}$ for $7 \mathrm{~d}$. Drug substance and drug product observed for photolytic stress were bestowed at light and dark for $14 \mathrm{~d}$. For thermal stress, solid samples of drug substance and drug product were entrusted in a controlled-temperature oven at room temperature and $70^{\circ}$ for $14 \mathrm{~d}$. A preparation of placebo was applied to all stressed condition.

\section{RESULTS AND DISCUSSION}

The described method has been validated for response function, accuracy, repeatability and intermediate precision. The nominal concentration of standard solutions was approximately $5 \mu \mathrm{g} / \mathrm{ml}$. The results of UV analysis have been shown in Tables 1-4. The proposed method was found to be linear with a linear correlation coefficient of 0.999 and the linear regression Eqn., $y=0.127 x+0.008$ (fig. 2). The minimum concentration levels at which diazepam can be reliably detected (LOD) and quantified (LOQ) were found to be 0.159 and $0.482 \mu \mathrm{g} / \mathrm{ml}$, respectively. The mean recoveries were 98.36-100.72\% substantiated the method as accurate (Table 1). The repeatability and intraday assay precision (RSD) was $<1 \%$ and the interday assay precision was $<2 \%$ revealed the proposed method as precise (Table 2).

Potency assay tests of four different brands of diazepam were performed by the proposed method. According to

\section{TABLE 1: ACCURACY STUDY}

\begin{tabular}{lcccc}
\hline Sample No. & \% Recovery level & Concentration given & Concentration obtained & \% Recovery mean \pm SD \\
\hline 1 & $80 \%$ & 9.128 & 8.978 & $98.36 \pm 0.04$ \\
2 & $90 \%$ & 9.644 & 9.594 & $99.48 \pm 0.27$ \\
3 & $100 \%$ & 10.160 & 10.137 & $99.77 \pm 0.04$ \\
4 & $110 \%$ & 10.676 & 10.696 & $100.18 \pm 0.03$ \\
5 & $120 \%$ & 11.192 & 11.273 & $100.72 \pm 0.07$ \\
\hline
\end{tabular}


TABLE 2: PRECISION STUDY

\begin{tabular}{lcccccccc}
\hline Sample & $\begin{array}{c}\text { \% Assay } \\
\text { No. }\end{array}$ & \multicolumn{3}{c}{ Intra-day assay } & \multicolumn{3}{c}{ Inter-day assay } \\
\cline { 3 - 8 } & (repeatability) & $\mathbf{1}^{\text {st }} \mathbf{h}$ & $\mathbf{3}^{\text {rd }} \mathbf{h}$ & $\mathbf{8}^{\text {th }} \mathbf{h}$ & $\mathbf{1}^{\text {st }} \mathbf{d}$ & $\mathbf{3}^{\text {rd }} \mathbf{d}$ & $\mathbf{5}^{\text {th }} \mathbf{d}$ & $\mathbf{7}^{\text {th }} \mathbf{d}$ \\
\hline 1 & 101.82 & 99.17 & 100.66 & 99.92 & 100.50 & 101.87 & 99.34 & 101.59 \\
2 & 101.88 & 99.33 & 100.52 & 99.90 & 97.00 & 100.96 & 100.71 & 101.02 \\
3 & 101.84 & 99.42 & 100.39 & 100.21 & 96.88 & 97.10 & 99.96 & 100.68 \\
4 & 101.71 & 99.55 & 100.21 & 99.58 & 98.94 & 101.15 & 101.09 & 99.02 \\
5 & 101.85 & 99.55 & 100.55 & 99.60 & 100.29 & 100.24 & 99.20 & 102.16 \\
6 & 101.33 & 99.51 & 100.55 & 99.70 & 100.22 & 100.50 & 100.24 & 99.67 \\
Mean \pm SD & $101.74 \pm 0.21$ & $99.42 \pm 0.15$ & $100.48 \pm 0.16$ & $99.82 \pm 0.24$ & $98.97 \pm 1.67$ & $100.30 \pm 1.67$ & $100.09 \pm 0.74$ & $100.69 \pm 1.17$ \\
$\%$ RSD & 0.21 & 0.15 & 0.16 & 0.24 & 1.68 & 1.66 & 0.74 & 1.17 \\
\hline
\end{tabular}

TABLE 3: DRUG CONTENT IN FOUR DIFFEREN BRANDS OF DIAZEPAM

\begin{tabular}{lcc}
\hline Sample no. & mg/tablet & Percentage \\
\hline$D_{1}{ }^{*}$ & 4.91 & $98.2 \%$ \\
$D_{2}{ }^{*}$ & 4.98 & $99.6 \%$ \\
$D_{3}{ }^{*}$ & 5.01 & $100.2 \%$ \\
$D_{4}{ }^{*}$ & 4.87 & $97.4 \%$ \\
\hline
\end{tabular}

*Four locally available brands of diazepam tablets coded as $D_{1}, D_{2}, D_{3}$ and $D_{4}$ purchased from domestic market

TABLE 4: SPECIFICITY STUDY

\begin{tabular}{|c|c|c|c|c|c|}
\hline \multicolumn{3}{|c|}{$\begin{array}{l}\text { Fixed drug substance spiked with different concentration } \\
\text { of excipient }\end{array}$} & \multicolumn{3}{|c|}{$\begin{array}{l}\text { Fixed excipient spiked with different concentration of } \\
\text { drug substance }\end{array}$} \\
\hline $\begin{array}{l}\text { Nominal drug } \\
\text { substance } \\
\text { concentration }(\mu \mathrm{g} / \mathrm{ml})\end{array}$ & $\begin{array}{c}\text { Excipient } \\
\text { concentration } \\
(\mu \mathrm{g} / \mathrm{ml}) \\
\end{array}$ & Absorbance & $\begin{array}{c}\text { Nominal excipient } \\
\text { concentration } \\
(\mu \mathrm{g} / \mathrm{ml})\end{array}$ & $\begin{array}{c}\text { Drug substance } \\
\text { concentration } \\
(\mu \mathrm{g} / \mathrm{ml})\end{array}$ & Absorbance \\
\hline \multirow{5}{*}{5.160} & 101.44 & 0.6709 & \multirow{5}{*}{126.8} & 4.128 & 0.5428 \\
\hline & 114.12 & 0.6799 & & 4.644 & 0.6096 \\
\hline & 126.8 & 0.6779 & & 5.160 & 0.677 \\
\hline & 139.48 & 0.6774 & & 5.676 & 0.7401 \\
\hline & 152.16 & 0.6861 & & 6.192 & 0.8012 \\
\hline
\end{tabular}

Regression Eqn., $y=0.0002 x+0.6515, R S D=0.804 \% ; y=0.1254 x+0.0268 ; R^{2}=0.9995$

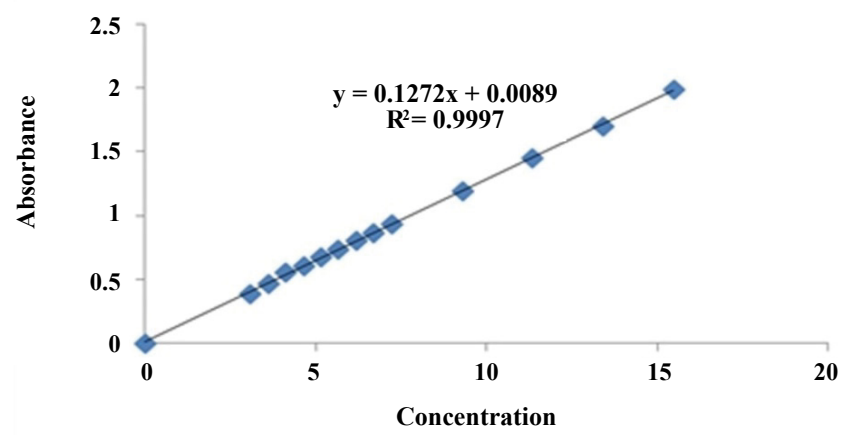

Fig. 2: Calibration curve of linearity study

USP $29^{[5]}$, diazepam tablets must contain $95-105 \%$ of the labelled amount of drug. All the brand products met the standard criteria with the new analytical method (Table 3).

Specificity is the ability of the method to measure the analytic response accurately in the presence of all potential components. Specificity of the proposed method is also confirmed by the stress study of the sample. The study was performed to validate stability indicating capability of the developed method and to identify the key factors, which will impact the stability of the drug product. The specificity was determined according to ICH guidelines by subjecting a sample solution and solid to accelerated degradation by acidic/ alkaline/neutral hydrolytic, oxidative, photolytic, and thermal stress conditions to evaluate the interference of degradation products in the quantitation of diazepam. The reported method provides data on specificity for their estimation in the presence of formulation excipients and degradants. The absorbance obtained with the mixture of the excipients showed no interference with the absorbance of standard (Table 4 and fig. 3). The percent assays of diazepam standard and marketed product under stressed condition at different observation days are listed in Table 5. To develop the stability indicating method, the UV spectrums of diazepam under several stressed condition were studied on UV/Vis spectrophotometer. When diazepam standard was subjected to neutral hydrolysis at room temperature, some minor degradants were generated (fig. 4A). On the other hand, neutral hydrolysis at $60^{\circ}$ gave a result of highly increased value with $135.93 \%$ 
www.ijpsonline.com
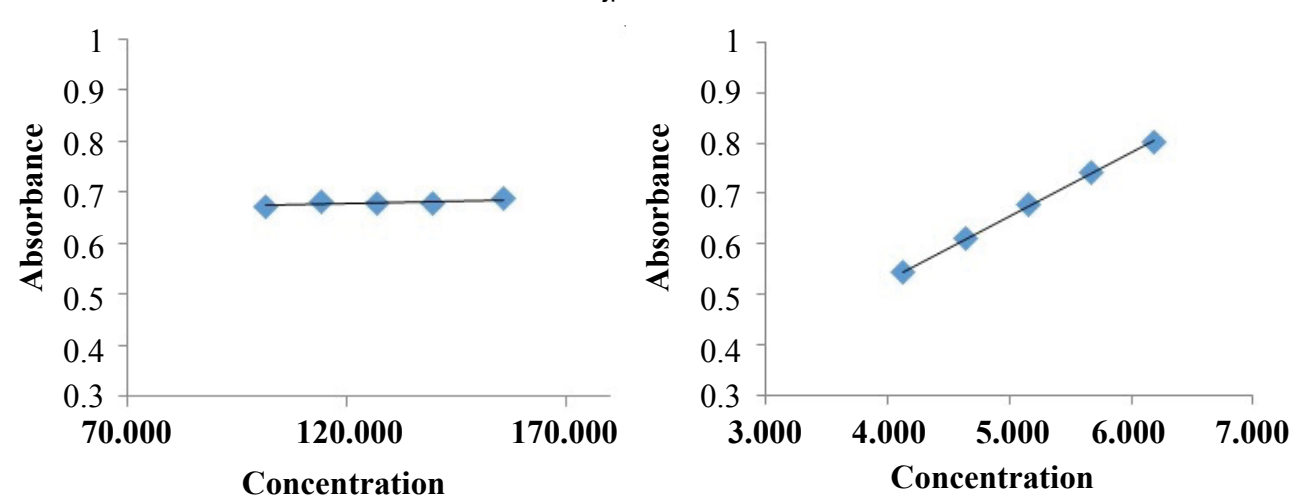

Fig. 3: Specificity study

TABLE 5: FORCED DEGRADATION STUDY

\begin{tabular}{|c|c|c|c|c|}
\hline Degradation type & Experimental conditions & Maximum degradation (d) & \% Assay of standard & \% Assay of product \\
\hline \multirow{7}{*}{ Hydrolysis } & Neutral hydrolysis at $\mathrm{RT}^{*}$ & 7th & 89.98 & 104.54 \\
\hline & Neutral hydrolysis at $60^{\circ}$ & 7th & 135.93 & 101.78 \\
\hline & Acid hydrolysis at RT* & 7th & 89.69 & 94.04 \\
\hline & \multirow{2}{*}{ Acid hydrolysis at $60^{\circ}$} & 5 th & 93.59 & 83.37 \\
\hline & & 7th & 112.93 & 142.35 \\
\hline & Base hydrolysis at $\mathrm{RT}^{*}$ & $3 r d$ & 59.79 & 66.78 \\
\hline & Base hydrolysis at $60^{\circ}$ & 1st & 37.80 & 72.78 \\
\hline \multirow{2}{*}{ Oxidation } & $30 \% \mathrm{H}_{2} \mathrm{O}_{2}$ at $\mathrm{RT}^{*}$ & 7th & 80.54 & 100.72 \\
\hline & $30 \% \mathrm{H}_{2} \mathrm{O}_{2}$ at $60^{\circ}$ & 7th & 106.76 & 108.29 \\
\hline \multirow{2}{*}{$\begin{array}{l}\text { Photolytic (solution } \\
\text { state) }\end{array}$} & Dark & 14 th & 108.64 & 106.68 \\
\hline & Light & 14 th & 102.48 & 142.28 \\
\hline \multirow{2}{*}{ Thermal (solid state) } & $\mathrm{RT}^{*}$ & 14th & 102.20 & 99.08 \\
\hline & $60^{\circ}$ & 14th & 111.72 & 104.83 \\
\hline
\end{tabular}

*RT: room temperature

in the assay (fig. 4B). There was no notable degradation for neutral hydrolysis of marketed product (figs. 4A and $3 \mathrm{~B})$.

Again a minor degradation was remarked for acid hydrolysis of both diazepam standard and marketed product when reacted with $0.1 \mathrm{~N} \mathrm{HCl}$ at room temperature (fig. 4C). However, after $5 \mathrm{~d}$ of observation, approximately $16 \%$ of diazepam standard and $17 \%$ of marketed product were found to be degraded due to acid hydrolysis at elevated temperature of $60^{\circ}$. Subsequently, after $7 \mathrm{~d}$ of observation the amount of diazepam and marketed product were highly increased with 112.93 and $142.35 \%$, respectively in the assay (fig. 4D).

A major degradation was observed for base hydrolysis. Here, after 3 rd d more than $20 \%$ of diazepam was degraded when reacted with $0.1 \mathrm{~N} \mathrm{NaOH}$ at room temperature (fig. 4E). Nevertheless, after 1st d of observation more than $20 \%$ of standard diazepam and marketed products were degraded because of base hydrolysis at elevated temperature of $60^{\circ}$ (fig. 4F).
Although, $20 \%$ of diazepam standard was degraded due to oxidation at room temperature (fig. 5A) no significant change was observed for oxidation at $60^{\circ}$ (fig. 5B).

Effect of photolytic stress was shown in fig. 5C. During photolytic stress testing in solution state, on day 14 the amount of degradation of marketed product kept under light was increased by $142.28 \%$ (fig. 5D), whereas no significant change was observed for diazepam standard and marketed product while kept protected from light (fig. 5C). After $14 \mathrm{~d}$ of observation the $\%$ assay of diazepam standard under thermal-stressed condition at room temperature (fig. 6A) and $60^{\circ}$ (fig. 6B) were 102.2 and $111.72 \%$, respectively. Hence, a brief thermal stress did not generate any degradants for diazepam standard and marketed product (fig. 6A and $\mathrm{B}$ ).

Absorbance of excipient increased at approximately 230 to $270 \mathrm{~nm}$ during basic hydrolysis, which increases at $60^{\circ}$ (fig 4F). The study also demonstrated that the excipient has no major effect in other stressed 


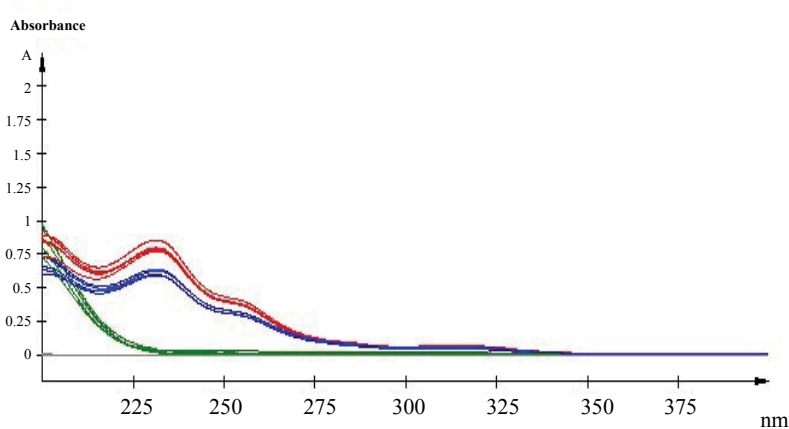

A

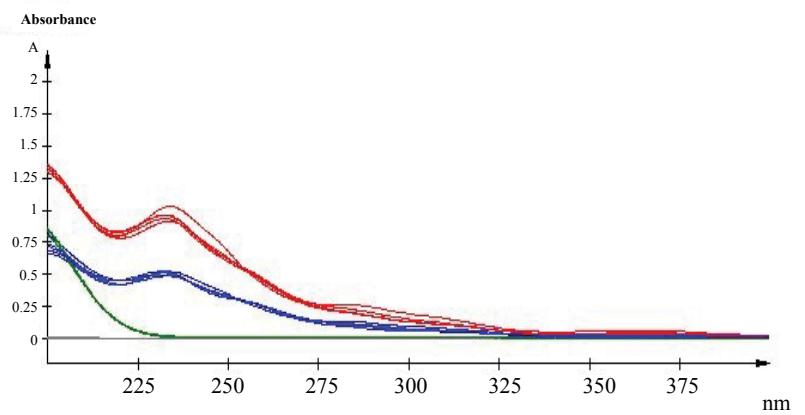

C

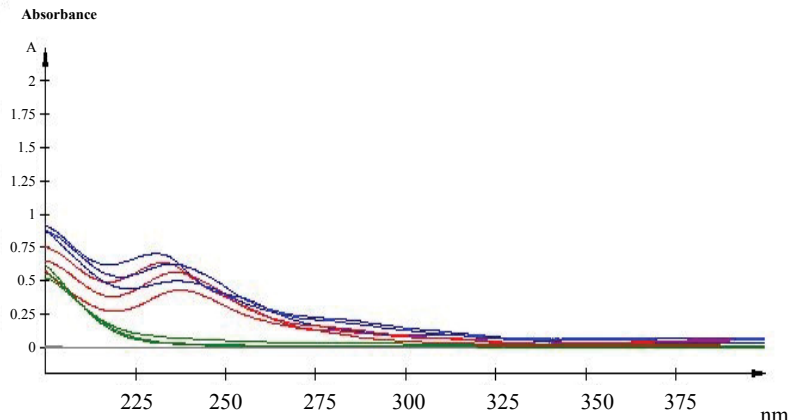

$\mathbf{E}$

Fig. 4: Overlain UV spectra of pH effect on diazepam

(A) Water hydrolysis effect at room temperature, (B) water hydrolysis effect at $60^{\circ},(\mathrm{C})$ acid hydrolysis effect at room temperature, (D) acid hydrolysis effect at $60^{\circ},(\mathrm{E})$ base hydrolysis effect at room temperature, (F) base hydrolysis effect at $60^{\circ}$

conditions on diazepam standard and marketed product (figs. 4 and 5).

Diazepam has shown a broad UV/Vis absorption profile at $231 \mathrm{~nm}$ (fig. 4). Some data showed a high increased value of drug product and substance. Such as, neutral hydrolysis on diazepam standard at $60^{\circ}$, acid hydrolysis at $60^{\circ}$, photolytic stress on marketed product at light and thermal stress on diazepam standard at $60^{\circ}$. These may occur due to formation of other side/degraded products, which may have similar absorption profile as diazepam. Acid hydrolysis of diazepam gives rise 2,4-dichloro-10-methylacridin-9$(10 \mathrm{H})$-one and 2,4-dichloroacridin-9-(10-H)-one ${ }^{[14]}$. Again, photolysis of diazepam gives rise nordiazepam, DIZ 3, DIZ 4, DIZ 6 and DIZ $7^{[15]}$. The absorbance pattern of diazepam was also changed with time and

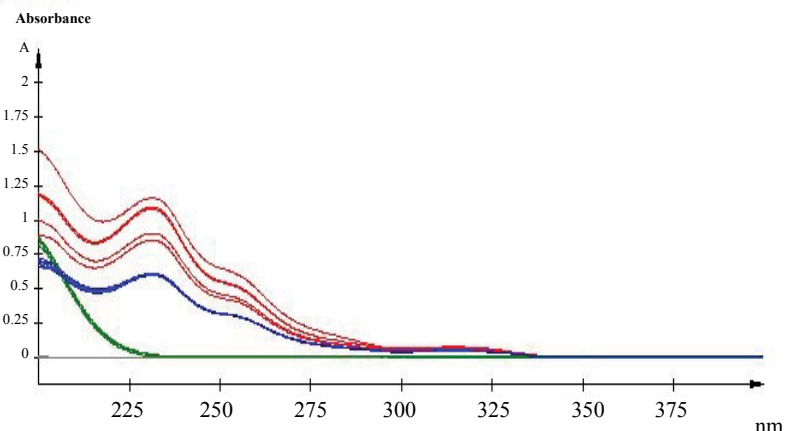

B

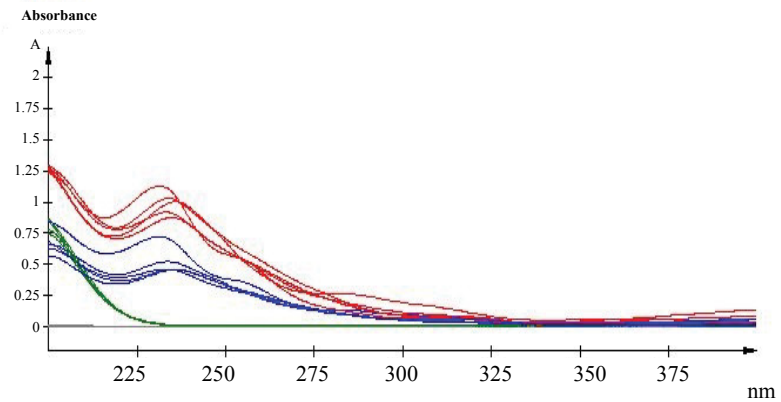

D

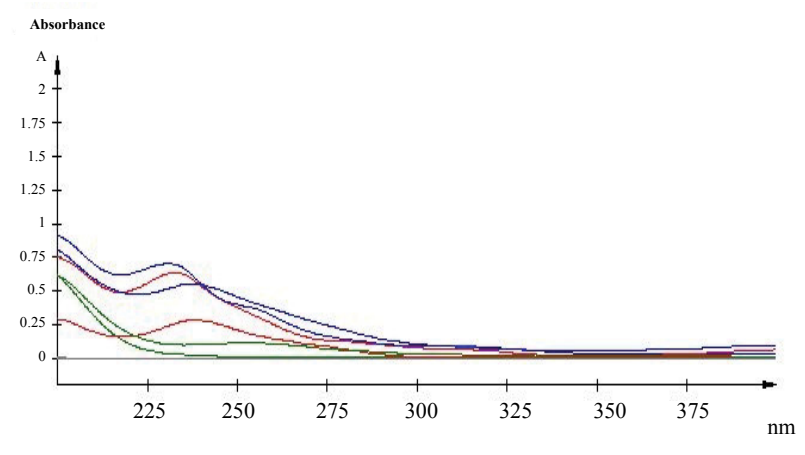

F

temperature. These all factors resulted in an overall effect on the assay of diazepam content in standard as well as marketed product. Although the degradation products had not been identified, the method had been able to detect the changes due to stress condition. Further analysis of the degradation product may be done through chromatographic separation of the degradants, followed by characterization through appropriate spectroscopic techniques such as mass spectroscopy and nuclear magnetic resonance spectroscopy. The results of the study thus provide an improved understanding of the degradation pathway of diazepam, stability indicating method development and selection of storage conditions.

The proposed UV/Vis spectrophotometric method was validated successfully in accordance to ICH Q2B 


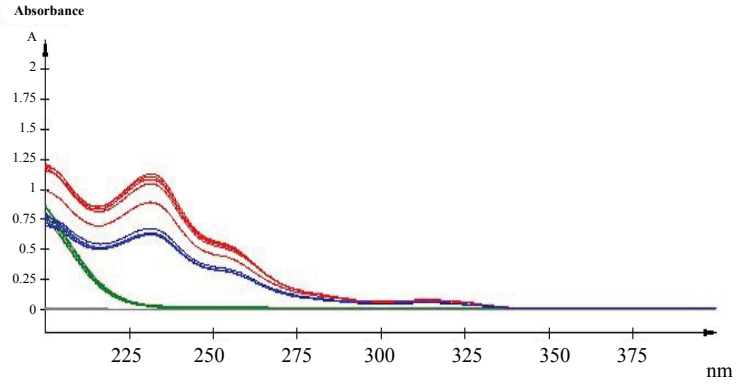

A

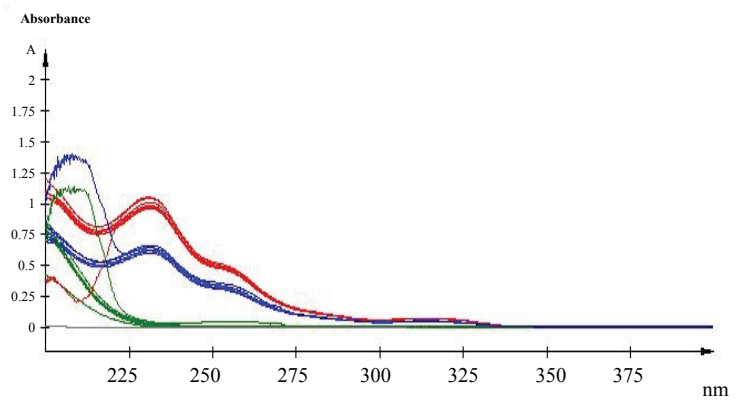

C

Fig. 5: Overlain UV spectra of oxidative stress effect on diazepam (A) Oxidation effect at room temperature, (B) oxidation effect at $60^{\circ},($ C) sample solution in dark, (D) sample solution in light

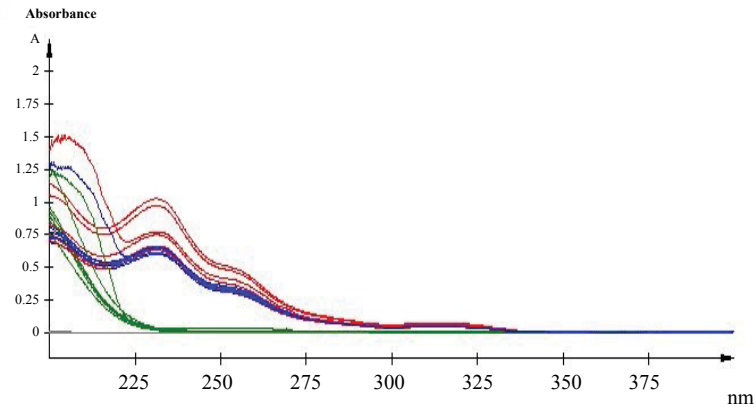

A

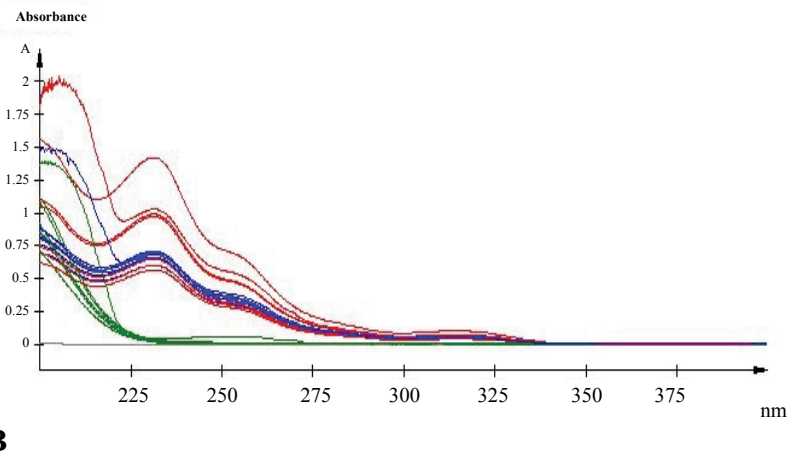

Fig. 6: Overlain UV spectra of thermal stress effect on diazepam at solid state

(A) Sample at room temperature, (B) sample at $60^{\circ}$

guideline. Based on the UV spectral results attained from the analysis of forced degraded samples using the proposed method, it can be concluded that the method is specific for determination of diazepam in presence of degradants. The method has linear response in stated range with a lower value of LOD and LOQ and is found to be accurate and precise. The stated method can be used as stability indicating method for assay of diazepam in tablet dosage form.

\section{Acknowledgements:}

The authors are grateful to Beximco Pharmaceuticals Ltd, Bangladesh for providing diazepam. The authors are also highly grateful to Pharmaceutical Sciences Research Division, Bangladesh Council of Scientific and Industrial Research (BCSIR) Laboratories, Dhaka,

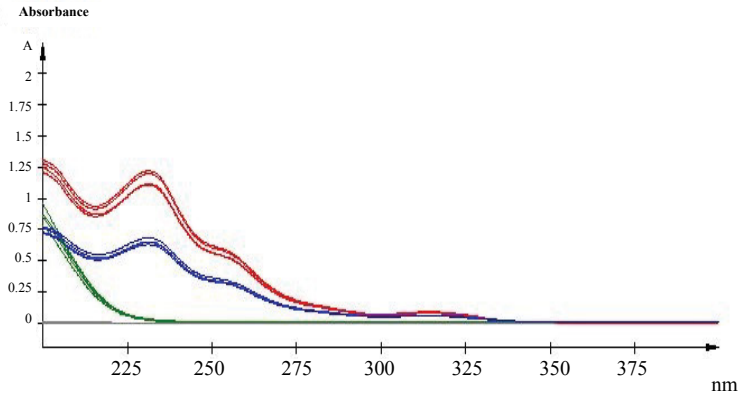

B

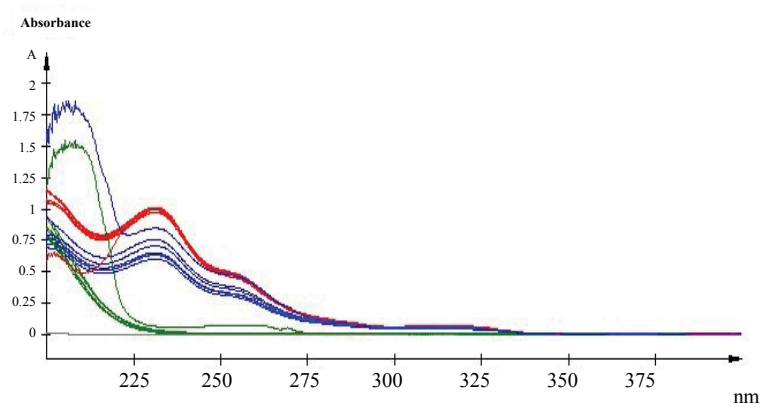

D 
HPLC method for simultaneous determination of amlodipine and benazepril hydrochloride from their combination drug product. J Pharma Biomed Anal 2005;39:147-55.

4. Blessy M, Ruchi DP, Prajesh NP. Development of forced degradation and stability indicating studies of drugs-A review. $\mathrm{J}$ Pharma Anal 2014;4:159-65.

5. USP 29, NF 24: the United States Pharmacopeia, the National Formulary. Vol. 30(1). Rockville, Maryland: United States Pharmacopeial Convention; 2006. p. 673.

6. Charney DS, Mihic SJ, Harris RA. Hypnotics and Sedatives. In: Brunton LL, Lazo JS, Parker KL. Goodman \& Gilman's: the Pharmacological Basis of Therapeutics. 11th ed. New York: McGraw-Hill Medical Publishing Division; 2006. p. 402-5.

7. Bertram GK, Susan BM, Anthony JT. Basic \& Clinical Pharmacology. 12th ed. New York: Lange Medical Publication; 2012. p. 373-86.

8. John MBJ, John HB. Wilson and Gisvold's Text book of Organic Medicinal and Pharmaceutical Chemistry. 12th ed. Philadelphia: Lippincott Williams \& Wilkins Publication; 2011. p. 443-7.

9. Andrejus K. Essentials of Medicinal Chemistry. 2nd ed.
Hoboken, New Jersey: A Wiley-Interscience Publication; 1998. p. 288.

10. Roland B, Erwin S. Benzodiazepines affect channel opening of GABAA receptors induced by either agonist binding site. Mol Pharmacol 2005;67:1005-8.

11. Siladitya B, Subhajit G, Fahad A, Saayak S, Sritoma B. UVVisible spectrophotometric method development and validation of assay of paracetamol tablet formulation. Anal Bioanal Techniques 2012;3:1-6.

12. https://www.fda.gov/downloads/drugs/guidances/ ucm073384.pdf.

13. http://www.ema.europa.eu/docs/en_GB/document_library/ Scientific_guideline/2009/09/WC500002651.pdf.

14. Gallardo Cabrera C, Goldberg de Waisbaum R, Sbarbati Nudelman N. Kinetic and mechanistic studies on the hydrolysis and photodegradation of diazepam and alprazolam. J Phys Org Chem 2005;18:156-61.

15. Jakimska A, Śliwka Kaszyńska M, Nagórski P, Kot Wasik A, Namieśnik J. Environmental fate of two psychiatric drugs, diazepam and sertraline: phototransformation and investigation of their photoproducts in natural waters. J Chromatogr Sep Tech 2014;5:253. 